\title{
Towards the understanding of the two wavelength laser cleaning in avoiding yellowing on stonework: a micro-Raman and LIBS study
}

\author{
Athanasia Papanikolaou ${ }^{1,2}$, Panayiotis Siozos ${ }^{1}$, Aggelos Philippidis ${ }^{1}$, Kristalia \\ Melessanaki ${ }^{1}$, Paraskevi Pouli ${ }^{1 \star}$ \\ 1 Institute of Electronic Structure and Laser, Foundation for Research and Technology-Hellas (IESL- \\ FORTH), P.O. Box 1385, 71110 Heraklion, Crete, Greece \\ 2 Department of Physics, University of Crete, 70013 Heraklion Crete, Greece \\ * Corresponding author: ppouli@iesl.forth.gr
}

\begin{abstract}
The synchronous use of Infrared (IR at $1064 \mathrm{~nm}$ ) and Ultraviolet (UV at $355 \mathrm{~nm}$ ) wavelengths of a Q-Switched Nd:YAG laser has been shown to efficiently confront the issue of discoloration, which may be observed upon laser ablation of environmental encrustation from marble surfaces, and thus this methodology is effectively employed in various laser cleaning applications. In order to further investigate the mechanisms that influence this result, a series of tests were undertaken on fragments of marble with environmental homogeneous compact crust. Through a number of irradiation tests applying a variety of laser parameters (individual use of IR and UV beams, as well as, their synchronous use) the different ablative processes have been investigated. In this paper, micro-Raman and Laser Induced Breakdown Spectroscopy (LIBS) were employed in order to examine the role of each laser beam, as well as their combination, and so to approach the reasons that induce yellow discoloration. The results of the above studies will be presented with the aim to further describe the two wavelength laser cleaning methodology and its principle, thus elucidating its effectiveness.
\end{abstract}

Keywords: Laser cleaning, pollution encrustation, yellowing, double wavelength, laser spectroscopy

\section{Introduction}

\subsection{The yellowing effect}

Outdoor Cultural Heritage (CH) monuments made of stone (marble, limestone etc.) are susceptible to a number of harmful environmental factors such as micro climate, acid rain, humidity and airborne particles from exhaustions of cars and factories. Due to these compounds a hard, dark-coloured crust is often developed on their surface. In an effort to remove the crust from the surface of the marble IR lasers were used but yellowing of the treated surfaces often appears as an undesirable side effect.

The discoloration effect has been extensively studied and a number of hypotheses explaining its origin have been developed through the last years [1-9]. A brief presentation of the prevailing explanations upon the yellowing hue on the irradiated surface is given here: 
- The revealing of pre-existing layers: According to this hypothesis, IR radiation removes the encrustation layer and reveals coloured pre-existing layers or "patinas". These layers may be either intentionally applied (i.e. to protect the original surface and/or as a preparation layer before the application of paints) or they may have been developed naturally (due to weathering effect). In both cases they are considered historical and must be safeguarded as they may contain valuable information, as for example sculpted details and tooling traces, as well as historical evidence about materials and techniques used (traces of colours/pigments etc.) [10].

- The change of the original colour of the stone surface; this alteration may be caused due to the migration of water soluble organic compounds from the encrustation to the underlying stone, which is favoured in environments with high humidity and rain. As a result, the surface revealed upon laser cleaning show a colour different to the expected one $[11,12]$.

- The chemical transformation of iron components after the irradiation with IR. According to this hypothesis, although the percentage of iron oxides in the encrustation is indeed very low $(\sim 0.6 \%[13])$, their chemical transformation may result into yellowing of the treated surfaces, which can be significant. Studies performed by different research groups have detected the presence of nanospheres rich in iron on the surface of technical samples containing hematite and graphite, after irradiation with IR [14], or the reduction of iron components present in pollution crusts, such as $\mathrm{Fe}_{2} \mathrm{O}_{3}$, into magnetite $\left(\mathrm{Fe}_{3} \mathrm{O}_{4}\right)$ [15]. Recently it has been suggested that both hematite $\left(\mathrm{Fe}_{2} \mathrm{O}_{3}\right)$ and goethite $(\alpha-\mathrm{FeO}(\mathrm{OH}))$ exist at the encrustation [9] and that yellowing can possibly be attributed to the transformation of hematite $\left(\mathrm{Fe}_{2} \mathrm{O}_{3}\right)$ to goethite $(\alpha-\mathrm{FeO}(\mathrm{OH}))$ or maybe maghemite $\left(\gamma-\mathrm{Fe}_{2} \mathrm{O}_{3}\right)$.

- The selective vaporization of black components and the preservation of a gypsum matrix on the marble's surface after the irradiation at $1064 \mathrm{~nm}$ below the ablation threshold. The dark coloured particles highly absorb the IR radiation and are removed from the surface leaving behind a gypsum matrix with very small holes in their place. The incident, on the surface, light is then differentially scattered (according to Rayleigh scatter) causing a shift to the cleaned surface towards yellow [16].

In order to approach this delicate issue, namely the discoloration of the treated surface of polluted marble following irradiation with IR laser beams, research efforts have been focused on the identification of the composition of the environmental encrustation $[13,17]$ in relation to the series of cleaning tests at different laser parameters $[5,9,18]$. Physicochemical analyses and evaluation of the treated surfaces and/or the material removed $[7,12,15,19]$ were also employed to further investigate the yellowing issue.

\subsection{The double wavelength methodology}

With the aim to overcome the challenge of laser induced yellowing, a laser cleaning methodology has been developed [20], in which two wavelengths from the same laser system are used simultaneously to effectively remove the encrustation from the marble's surface without changes to its colour, chemistry or delicate structure. The success of this methodology relies on the blending of an IR and a UV beam, at a specific ratio and fluence values, which provides the opportunity to efficiently remove the encrustation. 
To further investigate the yellowing effect and understand the mechanisms of the two-wavelength blending, a series of studies were undertaken. They involved tests using different laser parameters (wavelengths, laser pulse duration, fluence values etc.) on technical samples simulating black crusts, as well as on real fragments.

It should be noted that pollution accumulations on outdoors stonework are particularly complex systems and their composition, morphology and stratigraphy may vary among monuments of different materials; located in different countries (depending on their climatic conditions, pollution level and history) and representing various historic eras. This is an important parameter to take into account when studying laser cleaning and interpreting analytical data for evaluation purposes.

This research has been focused on the investigation of fragments of minor historic value taken from the Athenian Acropolis. Analytical techniques provided the chemical and molecular composition of the samples before and after laser irradiation in order to understand the physicochemical processes taking place while using two laser wavelengths separately or simultaneously.

\section{Materials and methods}

\subsection{Samples}

Irradiation tests were performed on a marble fragment with real environmental homogeneous thin compact crust. The fragment is part of a freshly-cut marble complement added onto the Parthenon Frieze in Athens, Greece, during the restoration actions by Balanos in 1960s. During this restoration marble pieces (of the same quarry in Pentelic mountain) have been added to replace miss- ing or damaged parts of the sculpted Frieze blocks. These complements bear the same accumulations with the rest of the Frieze and thus have been chosen for the purpose of this study [4].

\subsection{Experimental parameters}

The laser irradiation tests were performed with a Q-Switched Nd:YAG nanosecond (ns) laser (a customised system of Spectron, series SL850) emitting in the first and third harmonic wavelengths, in the infrared (IR, 1064nm) and ultraviolet (UV, $355 \mathrm{~nm}$ ) respectively. The laser provides the opportunity to emit each of the wavelengths separately and simultaneously. When the two beams are used simultaneously, the operator has the opportunity to select the fluence (F, measured in $\mathrm{J} / \mathrm{cm}^{2}$ ) output of each beam in order to get different ratios of the fluence of the IR $\left(\mathrm{F}_{\mathrm{IR}}\right)$ and the UV $\left(\mathrm{F}_{\mathrm{UV}}\right)$ beams. Thus it is possible to select a final output ratio $\mathrm{F}_{\mathrm{IR}} /$ $F_{U V}=1 / 4$ or $4 / 1$ and therefore get a different cleaning result. It should be noted that the decision on the ratios presented in this paper is the result of extensive past studies [5].

A marble fragment covered with environmental homogeneous thin compact crust was irradiated in a variety of laser parameters (fluence value, number of pulses for each beam, as well as their combination). Three clearly distinctive in colour and effectiveness, cleaning results have been chosen for this study and are indicated in Fig. 1. Specifically, the area on the left side of Fig. 1 was irradiated at $1064 \mathrm{~nm}$ with 5 pulses of fluence $\mathrm{F}=0.8 \mathrm{~J} / \mathrm{cm}^{2}$. The middle area was irradiated with the same number of pulses at $355 \mathrm{~nm}$ and $\mathrm{F}=0.2 \mathrm{~J} / \mathrm{cm}^{2}$. A combination of the two beams (in synchronous mode) in the same fluence values (in ratio $\mathrm{F}_{\mathrm{UV}} / \mathrm{F}_{\mathrm{IR}}=1 / 4$ ) was used for the area shown in the right side of 
Fig. 1. The fluence values shown correspond to the cleaning thresholds of this crust in both wavelengths. The tests were performed in dry conditions and the laser was operating in low repetition rate $(3 \mathrm{~Hz})$. high sensitivity with low dark counts. The objective lens used for these analyses was $\times 20$ and the beam power on the sample was adjusted at $30 \mathrm{~mW}$. Typical exposure time on the CCD was 30 s per scan and the spectra

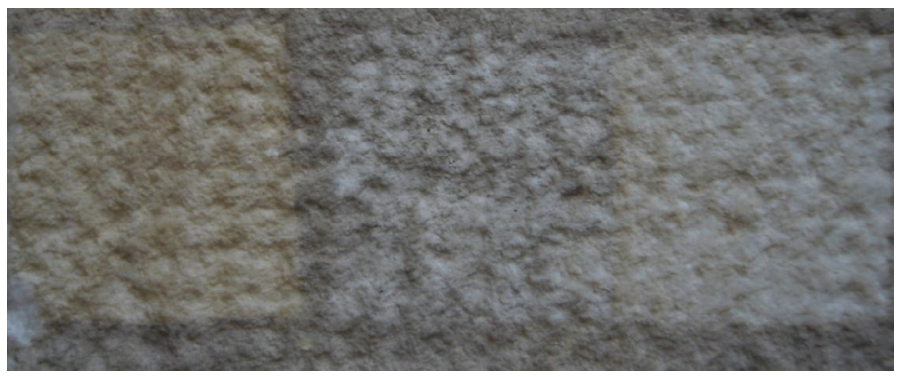

Fig. 1. Detail of marble

fragment with environmental homogeneous thin compact crust after laser irradiation tests: (left) $1064 \mathrm{~nm}, \mathrm{~F}=0.8$ $\mathrm{J} / \mathrm{cm}^{2}$, (middle) $355 \mathrm{~nm}$, $\mathrm{F}=0.2 \mathrm{~J} / \mathrm{cm}^{2}$ and (right) their synchronous application, $\mathrm{F}_{\mathrm{UV}} / \mathrm{F}_{\mathrm{IR}}=1 / 4$ (each square is $\left.2 \times 2 \mathrm{~cm}^{2}\right)$.

\subsection{Analytical Documentation}

\section{Raman spectroscopy}

Raman analysis was applied before and after laser irradiation on the real marble samples with the aim to detect possible variations on the molecular composition of the surface. The mobile Raman spectrometer (HE 785, Horiba-Jobin Yvon, France) was employed with excitation at $785 \mathrm{~nm}$ provided by a cw (continuous wave) diode laser coupled to an optical head ([21, 22]). A light-emitting diode (LED) and a high resolution colour camera (video microscope) are also part of the optical head and offer a very clear view of the area under investigation, necessary for positioning the beam on individual areas. The scattered radiation is collected through the objective lens, passes through an edge filter that cuts off Rayleigh scattering, and finally is focused into an optical fiber that is fed into a compact spectrograph, equipped with a concave grating, which provides spectral coverage in the range of $120-3395 \mathrm{~cm}^{-1}$ at a spectral resolution of about $10-15 \mathrm{~cm}^{-1}$. The detector, a Synapse TM CCD (1024 $\times$ 256 pixels), is Peltier-cooled and features recorded correspond to an average of 2 consecutive scans of the same point.

\section{LIBS Spectroscopy}

Laser induced breakdown spectroscopy (LIBS) was used aiming to detect and analyse the chemical composition of the samples surface before and after the laser treatment with a variety of parameters. The mobile LIBS spectrometer (LMNTII+), developed and constructed at IESL-FORTH, was used for this study [21,22]. The instrument uses a compact passively Q-switched Nd:YAG laser emitting pulses at $1064 \mathrm{~nm}(10 \mathrm{~mJ} /$ pulse, $10 \mathrm{~ns}$ ). Pulses are focused by means of plano-convex lens $(f=+75 \mathrm{~mm})$ on the surface of the object. The plasma emission is collected through the same lens and transmitted via an optical fiber that splits it into a dual spectrometer unit (Avaspec-2048-2-USB2, Avantes) that records emission spectra across a wavelength range extending from 200 to $660 \mathrm{~nm}$, with resolution of about $0.2-0.3 \mathrm{~nm}$. The laser along with necessary optics and a miniature CCD camera are integrated in a light-weight optical probe head. The camera offers a magnified view of the object surface 
during the analysis and permits accurate aiming of the laser beam with the aid of a cross-hair indicator superimposed on the image. All LIBS spectra were collected with a time-delay of $1.3 \mu$ s with respect to the laser pulse and for an integration time of 1 ms. A nearly circular spot with a diameter of about $150-300 \mu \mathrm{m}$ is probed by the laser beam.

\section{Results and discussion}

\subsection{Visual evaluation}

Visual observation of the sample shows that the areas treated with IR irradiation appear yellow, areas treated with UV irradiation are grey while the ones treated with both beams, simultaneously, are closer to the colour expected in this case.

\subsection{Raman evaluation}

Upon microRaman analysis calcite $\left(\mathrm{CaCO}_{3}-157,285\right.$ and $\left.1088 \mathrm{~cm}^{-1}\right)$ and/or gypsum $\left(\mathrm{CaSO}_{4} \cdot 2 \mathrm{H}_{2} \mathrm{O}-1009 \mathrm{~cm}^{-1}\right)$ were detected on the homogeneous thin compact crust as well as on all the surfaces treated either with IR and UV, separately or simultaneously. An intense fluorescent signal (Fig. 2) was observed on the crust and the area irradiated at $1064 \mathrm{~nm}$, though this is clearly reduced on areas irradiated at $355 \mathrm{~nm}$ or with the combination of 1064 and $355 \mathrm{~nm}$. The origin of the fluorescence can be attributed to organic compounds previously detected on the homogeneous thin compact crust [6]. Indeed, studies on pollution accumulations (on marble and limestone) by means of GC-MS detected a number of components, part of which show intense fluorescence.

The presence of these fluorescent compounds indicates that either these com-

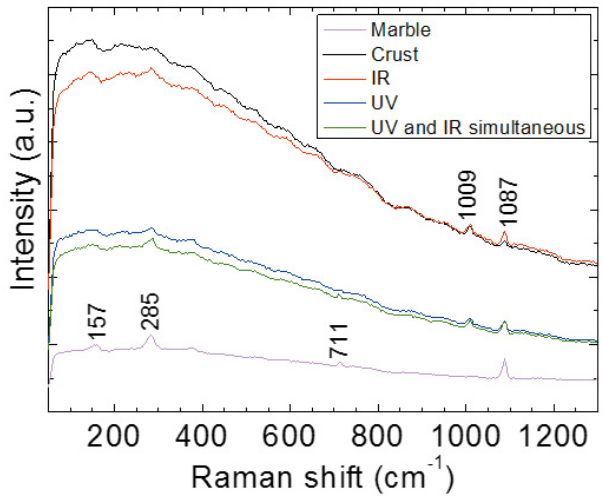

Fig. 2. Raman spectra acquired from the marble fragment presented in Fig. 1. Crust and areas treated with IR exhibit an intense fluorescence, while areas irradiated with UV or the combination of the 2 beams have a lower fluorescence, which is closer to the one of marble.

pounds were not affected, and thus they were not removed, upon IR irradiation, or they could possibly be induced by the laser beam as indicated by Oliveira et al. in their study [18]. Further analysis is currently performed in order to respond to this question. Among the arguments that support the first hypothesis (fluorescing compounds not removed by the IR laser beam) is that the fluorescing signal was detected on the sample prior to its irradiation/cleaning and the intensities of the Raman spectra recorded from the IR treated and reference areas are comparable. No additional fluorescence signal was detected after the IR radiation and thus the hypothesis that the detected fluorescence is due to IR laser irradiation seems unlikely for our samples. On the other hand, the reduction of the fluorescence after UV irradiation implies the removal of this fluorescent material from the surface of the sample. This difference in the Raman spectra of the irradiated areas suggests that the ablation occurs in a different and probably preferential/selective way for the two wavelengths. 


\subsection{LIBS analysis}

LIBS analysis on the same areas of the sample detected the presence of a number of elements with most important $\mathrm{Ca}, \mathrm{Al}, \mathrm{Fe}$, $\mathrm{Mg}, \mathrm{Si}$ and $\mathrm{Na}$. Characteristic spectra from these measurements are presented in Fig. 3. In order to detect and investigate the possible alterations in the elemental composition of the laser irradiated areas, either separately or simultaneously, the ratio of the chemical elements $\mathrm{Fe}$ and $\mathrm{Ca}$ was studied. The major components of the encrustation are $\mathrm{Fe}, \mathrm{Si}$ and $\mathrm{Mg}[17,23]$ but on the basis of previous research indicating that Fe holds a significant role in laser yellowing, our study was focused on the Fe concentration and behaviour for different irradiation parameters. In order to
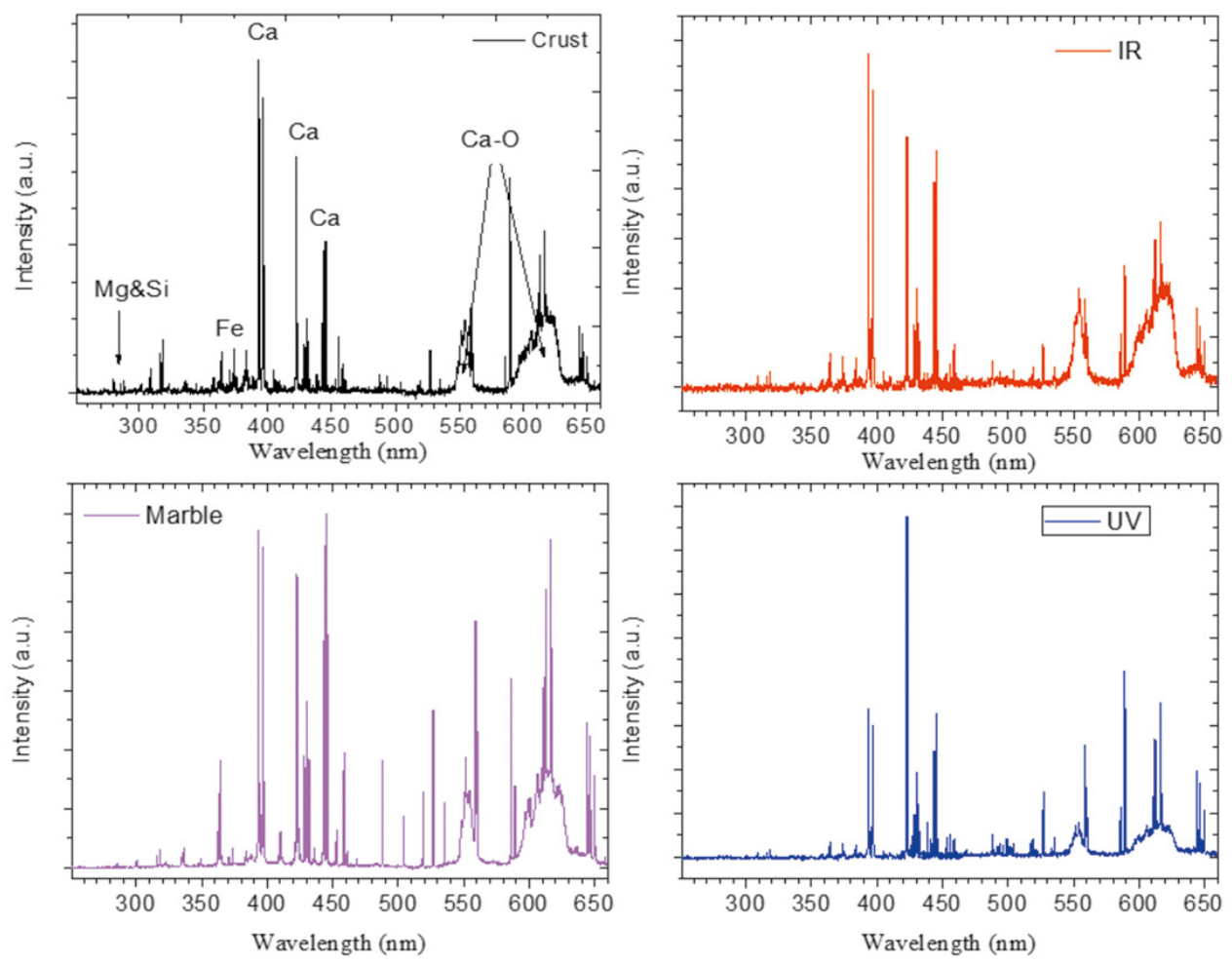

achieve accurate results, the detected signal intensity of the Fe peak was normalized with another element that exhibits a constant concentration. The selected component was Ca since its presence is homogenous among the sample. Therefore, data analysis was performed by investigating the ratio of $\mathrm{Fe} / \mathrm{Ca}$ for each irradiation parameter.

The proper selection of spectral lines was very important for achieving accurate results. The spectral lines chosen for this study are $\mathrm{Fe} 438.354 \mathrm{~nm}$ and $\mathrm{Ca} 445.478 \mathrm{~nm}$. Calcium (Ca) exhibits a number of emission spectral lines but $445.478 \mathrm{~nm}$ was chosen because it originates from a highly excited state with big excitation energy and therefore

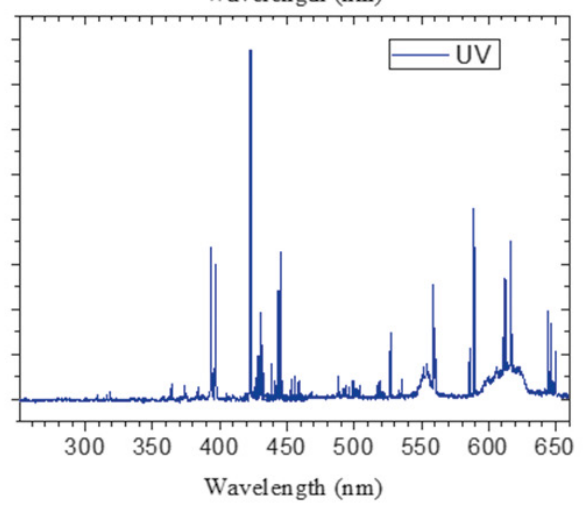
low self-absorption possibility. The available

Fig. 3. LIBS Spectra obtained from the marble fragment prior (crust and marble reference) and after laser irradiation (with IR and UV beams). 
spectral lines for iron are at 302.064, 371.994, 374.556 and $385.991 \mathrm{~nm}$ in the UV range and $438.354,440.475 \mathrm{~nm}$ in the visible region of the LIBS spectrum. The spectral lines at $371.994,374.556$ and $385.991 \mathrm{~nm}$ coincide with the molecular emission band of the $\mathrm{CN}$, and thus cannot be used. Furthermore, the line at $302 \mathrm{~nm}$ is too weak to provide reliable results. Therefore, the line at $438 \mathrm{~nm}$ has been used for the analysis because it has a higher intensity than the one at $440 \mathrm{~nm}$. Of significant importance is the average value, taken from 10 different spots/points on the studied areas, of the ratio corresponding to the first LIBS pulse of each irradiation condition. It was decided to take into account for our measurements only the first LIBS pulse as, due to ablation, any additional pulse will represent a different/altered surface. Figure 4 shows the average value of $\mathrm{Fe} / \mathrm{Ca}$ ratio for each irradiation parameter (described before in the caption of Fig. 1). A significant proportion of iron $(\mathrm{Fe})$ to calcium $(\mathrm{Ca})$, and therefore a greater concentration of iron, is tion than the area treated simultaneously with IR and UV. In addition, the reference marble has the lowest proportion of $\mathrm{Fe} / \mathrm{Ca}$ and it is comparable to the area treated with IR and UV simultaneously. The above lead to the conclusion that IR radiation removes preferentially the iron compounds, and thus that the ablation occurs in a selective way. On the other hand, the selective removal of the iron compounds does not occur upon UV irradiation, while the simultaneous use of both wavelengths shows the most efficient iron removal and results into a surface very similar, in iron concentration, to the one of the marble.

\section{Conclusions}

In summary, analytical investigation on a marble fragment with thin environmental homogeneous compact crust, which was irradiated with different laser beams and parameters, allows us to further under-

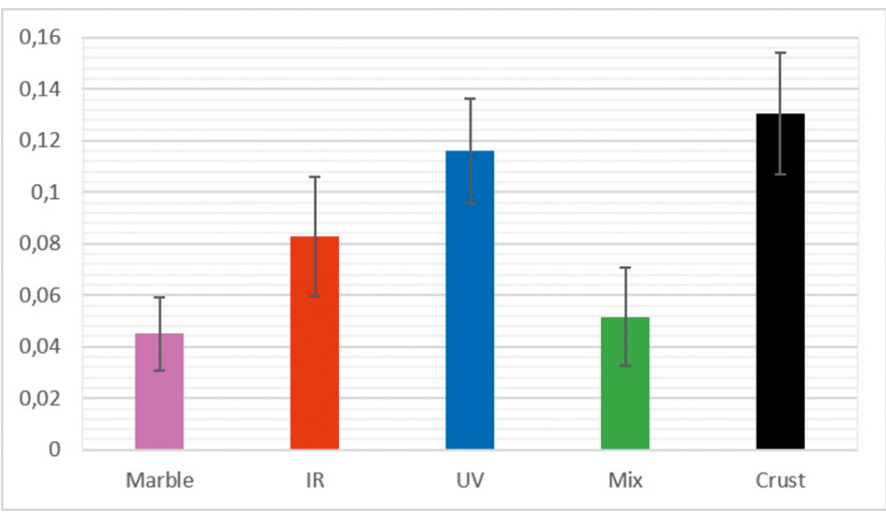

Fig. 4. The average Fe/ Ca ratio obtained from the first pulse of the LIBS spectra accumulated from 10 different spots for each of the irradiated areas. The error bars correspond to the standard deviation of the Fe/ Ca ratio. detected in areas with crust deposits and areas treated with UV radiation. Furthermore, the area treated with IR presents a lower ratio value, compared to the one irradiated with UV or the crust, but higher iron concentra- stand the ablation mechanisms that can be significant upon irradiation with different laser wavelengths. Optical observation confirmed the different ablation processes that take place upon irradiation with IR and 
UV wavelengths, and/or their combination, and thus to the final colour of the treated surface. Raman spectroscopy showed reduced fluorescence on the areas treated with UV wavelength (or where UV was involved), suggesting a selective removal of organic/fluorescing compounds from the surface of the sample in this laser ablation regime. On the contrary ablation with IR, at the fluence values employed in this study, does not remove the bulk of the crust and possibly these fluorescing particulates that are trapped therein. The hypothesis that this ablative regime may cause the presence of these types of fluorescing has been also examined. In addition, LIBS analysis detected a lower Fe concentration in the area treated with IR suggesting the selective removal of iron particles from the marbles surface, in contrast with areas irradiated with UV wavelengths.

Taking all the above into account, it is suggested that the ablation mechanisms occurring during the irradiation of environmental homogeneous compact crust from stonework are closely dependant to the beam wavelength. On the basis of the different absorption properties of the involved materials to the applied laser wavelength, it has been shown that different removal processes vary significant in each case. Our hypothesis is that upon UV irradiation organic fluorescing components are preferentially removed while upon IR irradiation Fe-rich particulates are effectively ablated, as shown by our LIBS measurements. By combining the two beams simultaneously dark coloured particles and organic/fluorescing compounds are equally removed from the crust, resulting thus into a homogeneous and efficient cleaning procedure. Of course, the ratio of the two beams is an important parameter in the whole process.
It has also to be noted that in our experiments the aim was to understand the ablative mechanisms rather than clean our samples. Therefore, for the purpose of our study it was important to irradiate the crust, but not remove it totally, in order to have a base for investigation. This remaining material, of different colour and composition, was analysed and studied. Further experiments are in progress, focused on the study of different ablation parameters through technical simulation samples and real marble fragments, in order to elucidate the ablation mechanisms and processes.

\section{References}

[1] P. Pouli, M. Oujja, and M. Castillejo, "Practical issues in laser cleaning of stone and painted artefacts: optimisation procedures and side effects", Applied Physics A, 106 (2012) 447-464, DOI: 10.1007/ s00339-011-6696-2.

[2] P. Pouli, V. Zafiropulos, and C. Fotakis, "The Combination of Ultraviolet and Infrared Laser Radiation for the Removal of Unwanted Encrustation from Stonework; a Novel Laser Cleaning Methodology" in: Proceedings of the $10^{\text {th }}$ International Congress on Deterioration and Conservation of Stone, Stockholm, Sweden, June 27-July 2, 2004, Daniel Kwiatkowski and Runo Lofvendahl (Eds.), ICOMOS, Sweden, 2004, pp. 315-322, ISBN: 9163114585.

[3] G. Marakis, P. Pouli, V. Zafiropulos, and P. Maravelaki-Kalaitzaki, "Comparative study on the application of the first and the third harmonic of a Nd:YAG laser system to clean black encrustation on marble", Journal of Cultural Heritage, 4 (2003) 83-91, DOI: 10.1016/S1296-2074(02)01208-6.

[4] P. Pouli E. Papakonstantinou, K. Frantzikinaki, A. Panou, G. Frantzi, C.Vasiliadis, and C. Fotakis, "The two-wavelength laser cleaning methodology; theoretical background and examples from its application on $\mathrm{CH}$ objects and monuments with emphasis to the Athens Acropolis sculptures", Heritage Science, 4 (2016) 9-20, DOI: 10.1186/s40494-016-0077-2. 
[5] P. Pouli, K. Frantzikinaki, E. Papakonstantinou, V.Zafiropulos, and C. Fotakis, "Pollution Encrustation Removal by Means of Combined Ultraviolet and Infrared Laser Radiation : The Application of this Innovative Methodology on the Surface of the Parthenon West Frieze" in: $5^{\text {th }}$ International Conference on Lasers in the Conservation of Artworks, LACONA V'03 Proceedings, Osnabrück, Germany, Sept. 15-18, 2003, K. Dickmann, C. Fotakis, and J. F. Asmus, (Eds.), Springer, Berlin Heidelberg, 2005,(100) pp. 333-340, DOI: $10.1007 / 3-540-27176-7 \_41$.

[6] P. Pouli, C. Fotakis, B. Hermosin, C. Saiz-Jimenez, C. Domingo, M. Oujja, and M. Castillejo., "The laser-induced discoloration of stonework; a comparative study on its origins and remedies" Spectrochimica Acta Part A: Molecular and Biomolecular Spectroscopy, 71 (2008) 932-945, DOI: 10.1016/j. saa.2008.02.031.

[7] C. de Oliveira, V. Vergès-Belmin, D. Demaille, and P. Bromblet, "Lamp black and hematite contribution to laser yellowing: A study on technical gypsum samples", Studies in Conservation, 61 (2016) 136-145, DOI: 10.1179/2047058415Y.0000000003.

[8] V. Vergès-Belmin and C. Dignard, "Laser yellowing: myth or reality?", Journal of Cultural Heritage, 4 (2003) 238-244, DOI: 10.1016/S12962074(02)01203-7.

[9] C. de Oliveira V. Vergès-Belmin, J. Lafait, M. Swider, C. Andraud, A. Tournié, and L. Galoisy, "Contribution of goethite to laser-induced stone yellowing”, Applied Physics A, 122 (2016) 467-476, DOI: 10.1007/s00339-016-9818-z.

[10] V. Vergès-Belmin, C. Pichot, and G. Orial, “Elimination de croutes noires sur marbre et craie : a quel niveau arreter le nettoyage?" in: Conservation of stone and other materials: proceedings of the international RILEM/UNESCO congress, UNESCO headquarters, Paris, June 29-July 1, 1993, E.\&F.N. Spon, London, UK, 1993, pp 534-541, ISBN:0419184104.

[11] S.S. Potgieter-Vermaak, R.H.M. Godoi, R. Grieken, J. H. Potgieter, M. Oujja, and M. Castillejo, "Micro-structural characterization of black crust and laser cleaning of building stones by micro-Raman and SEM techniques", Spectrochimica Acta Part A: Molecular and Biomolecular Spectroscopy, 61 (2005) 2460-2467, DOI : 10.1016/j.saa.2004.09.010.
[12] M. Gavino, B. Hermosin, M. Castillejo, M. Oujja, E. Rebollar, V. Vergès-Belmin, W. Nowik, and C. Saiz-Jimenez, "Black crusts removal: the effect of stone yellowing and cleaning strategies" in: Air Pollution and Cultural Heritage (Proceedings of the International workshop on Air Pollution and Cultural Heritage), Seville, Spain, December 1-3, 2003, C. Saiz-Jimenez (Ed.), London: AA Balkema, 2004, pp 239-245, DOI: 10.1201/b17004-37.

[13] P. Maravelaki-Kalaitzaki, "Black crusts and patinas on Pentelic marble from the Parthenon and Erechtheum (Acropolis, Athens): Characterization and origin", Analytica Chimica Acta, 532 (2005) 187-198, DOI: 10.1016/j.aca.2004.10.065.

[14] S. Klein, F. Ferksanati, J. Hildenhagen, K. Dickmann, H. Uphoff, Y. Marakis, and V. Zafiropulos, "Discoloration of marble during laser cleaning by Nd:YAG laser wavelengths", Applied Surface Science, 171 (2001) 242-251 DOI: 10.1016/S01694332(00)00706-6.

[15] M. Gracia, M. Gaviño, V. Vergès-Belmin, B. Hermosin, W. Nowik, and C. Sáiz-Jiménez, "Mössbauer and XRD Study of the Effect of Nd:YAG-1064 nm Laser Irradiation on Hematite Present in Model Samples", in: Lasers in the Conservation of Artworks: LACONA V Proceedings, Osnabrück, Germany, Sept. 15-18, 2003, K. Dickmann, C. Fotakis, and J. F. Asmus, (Eds.), Springer, Berlin Heidelberg, 2005, pp. 341-346, DOI: 10.1007/3-540-27176-7_42.

[16] V. Zafiropulos, P. Pouli, V. Kylikoglou, P. Maravelaki-Kalaitzaki, B. S. Luk'yanchuk, and A. Dogariu, "Synchronous Use of IR and UV Laser Pulses in the Removal of Encrustation: Mechanistic Aspects, Discoloration Phenomena and Benefits", in: Lasers in the Conservation of Artworks: LACONA V Proceedings, Osnabrück, Germany, Sept. 15-18, 2003, K. Dickmann, C. Fotakis, and J. F. Asmus, (Eds.), Springer, Berlin Heidelberg, 2005, pp. 311-318,. DOI: 10.1007/3-540-27176-7_38.

[17] P. Maravelaki-Kalaitzaki, D. Anglos, V. Kilikoglou, and V. Zafiropulos, "Compositional characterization of encrustation on marble with laser induced breakdown spectroscopy", Spectrochimica Acta Part B:Atomic Spectroscopy, 56 (2001) 887-903, DOI: 10.1016/S0584-8547(01)00226-9. 
[18] C. de Oliveira, P. Bromblet, A. Colombini, and $\mathrm{V}$. Vergès-Belmin, "Medium-wave ultraviolet radiation to eliminate laser-induced yellowing generated by the laser removal of lamp black on gypsum", Studies in Conservation, 60 sup1 (2015) S34-S40, DOI: 10.1179/0039363015Z.000000000205.

[19] C. De Oliveira, V. Vergès-Belmin, D. Demaille, and P. Bromblet, "Lamp black and hematite contribution to laser yellowing: A study on technical gypsum samples.", Studies in Conservation, 61 (2016) 136-145, DOI: 10.1179/2047058415Y.0000000003.

[20] K. Frantzikinaki, G. Marakis, A. Panou, C. Vasiliadis, E. Papakonstantinou, P. Pouli, T. Ditsa, V. Zafiropulos, and C. Fotakis, "The Cleaning of the Parthenon West Frieze by Means of Combined IRand UV-Radiation", in: Lasers in the Conservation of Artworks (Proceedings of LACONA VI conference), Vienna, Austria, September 21-25, 2005, J. Nimmrichter, W. Kautek, and M. Schreiner, (Eds.) Springer
Verlag, Berlin Heidelberg 2007, pp. 97-104, DOI: 10.1007/978-3-540-72310-7_12.

[21] P. Westlake et al., "Studying pigments on painted plaster in Minoan, Roman and Early Byzantine Crete. A multi-analytical technique approach", Analytical and Bioanalytical Chemistry, 402 (2012) 1413-1432, DOI: 10.1007/s00216-011-5281-z.

[22] Z.E. Papliaka, A. Philippidis, P. Siozos, M. Vakondiou, and K. Melessanaki, "A multi-technique approach, based on mobile / portable laser instruments, for the in situ pigment characterization of stone sculptures on the island of Crete dating from Venetian and Ottoman period", Heritage Science, 4 (2016) 1-18, DOI: 10.1186/s40494-016-0085-2.

[23] P. V Maravelaki, V. Zafiropulos, V. Kilikoglou, M. Kalaitzaki, and C. Fotakis, "Laser-induced breakdown spectroscopy as a diagnostic technique for the laser cleaning of marble", Spectrochimica Acta Part B: Atomic Spectroscopy, 52 (1997) 41-53, DOI: 10.1016/S0584-8547(96)01573-X. 